\title{
NORMAS A SEREM OBSERVADAS EM PROCEDIMENTOS BÁSICOS DE ENFERMAGEM
}

\author{
Nara Sena de Paula* \\ Maria Helena de Oliveira Marques** \\ Yoriko Kamiyama*** \\ Wanda de Aguiar Horta****
}

PAUlA, N. S. de; MARQUES, M. H. de O.; KAMIYAMA, Y.; HORTA, W. de A. Normas a serem observadas em procedimentos básicos de enfermagem. Rev. Esc. Enf. USP, São Paulo, 13(3):233-250, 1979.

As autoras apresentam, como material auxiliar de ensino, um guia de alguns procedimentos básicos de enfermagem, abordados segundo normas a serem observadas.

\section{INTRODUÇÃO}

A publicação deste material tem por objetivo apresentar procedimentos de enfermagem abordados à luz de princípios ou normas a serem obedecidas sem a preocupação da memorização da seqüência.

Esta abordagem visa melhor execução das atividades de enfermagem, pois, estando o executante atento para as normas que levam a uma determinada ação, pode realizar as tarefas mais corretamente do que quando as executa por simples aprendizagem seqüencial.

O material tem sido usado com êxito há oito anos na Escola de Enfermagem da Universidade de São Paulo, na disciplina Fundamentos de Enfermagem do Curso de Graduação, como material auxiliar de ensino, acompanhado de fundamentação teórica sobre o assunto, demonstração da técnica e prática pelo aluno. Esta prática, em alguns procedimentos como arrumação de cama, banho no leito e limpeza de unidade é realizada diretamente no hospital, em situação real; em outros procedimentos como verificação de sinais vitais e colheita de sangue, a prática é inicialmente realizada no laboratório de enfermagem, sendo utilizado os próprios alunos, aos pares, como executante e paciente; e, em outros procedimentos como cateterismo vesical e curativo, a prática é realizada também em primeira instância no laboratório de enfermagem, entretanto, utilizado o boneco como paciente.

Em qualquer dos casos, os procedimentos são posteriormente praticados no hospital, quer como atividade específica do aluno, em escala específica para um determinado procedimento, quer como atividade inserida dentro do contexto de estágio, no qual o aluno se incumbe dos cuidados gerais do paciente.

\footnotetext{
* Professor Assistente Doutor da disciplina Fundamentos de Enfermagem da EEUSP.

** Professor Assistente da disciplina Enfermagem Pediátrica da EEUSP. Mestre em Enfermagem.

*** Professor Livre Docente da disciplina Enfermagem em Doenças Transmissiveis da EEUSP.

**** Professor Titular da disciplina Fundamentos de Enfermagem da EEUSP.
} 
Propõe-se que, uma vez ensinado um procedimento em sala de aula ou laboratório de enfermagem, o aluno tenha a oportunidade de realizá-la em situação real, em tempo o mais próximo possível da aprendizagem teórica.

Espera-se que o presente guia seja útil não só para alunos de graduação em enfermagem, como também para os de cursos técnicos e de auxiliares de enfermagem. Além disso, poderá ser utilizado na elaboração de programas de treinamento em serviço para qualquer categoria funcional da equipe de enfermagem, inclusive $o$ atendente.

\section{LIMPEZA DE UNIDADE}

\section{MATERIAL NECESSARIO:}

- balde com água quente

- sabão em recipiente (ou desinfetante ou detergente)

- dois panos: um para lavar

um para anxugar.

\section{NORMAS A SEREM OBSERVADAS}

1. Preparar o ambiente de modo a que favoreça o trabalho

2. Preparar o material

3. Executar a limpeza:

- considerar áreas limpas e contaminadas (da área menos suja para a mais suja e da menos contaminada para a mais contaminada);

- considerar três etapas para limpeza de cada área: lavar com sabão, removê-lo totalmente e enxugar;

- utilizar movimentos amplos e sem repetição para remover sujidades;

- trocar a água e lavar os panos quando julgar necessário;

- evitar sujar áreas que foram limpas;

- evitar molhar ou sujar o chão durante a limpeza;

- aproveitar os raios solares como auxiliares na desinfecção.

4. Considerando que a unidade hospedará o paciente durante toda sua permanência no hospital, deixá-la em condições favoráveis à terapêutica do paciente.

5. Considerar o princípio básico de enfermagem que se relaciona a "proteger o homem contra agentes agressores externos".

OBSERVAÇÕES: Como boa norma administrativa, o atendente deverá ser, preferentemente, o membro da equipe de enfermagem responsável por este trabalho, sob supervisão do enfermeiro. 


\section{CUIDADO DIÁRIO DA UNIDADE}

\section{MATERIAL NECESSARIO:}

- lençóis

- colcha

- fronha

- pano úmido em recipiente.

\section{NORMAS A SEREM OBSERVADAS}

1. Remover todo o material sujo ou stipérfluo da cama, da unidade ou do quarto.

2. Trazer o material e colocá-lo de modo a faciltar o trabalho.

3. Executar a arrumação:

- remover a roupa da cama;

- arrumar, na cama sucessivamente, as peças de roupa de forma a que no final do trabalho estejam: limpas, secas, esticadas, presas e agradáveis à vista;

- lembrar que o trabalho será facilitado, se a cama for arrumada primeiro de um lado e depois o outro;

- esticar os lençöis søgurando-os pelas extremidades ao invés de alisá-los;

- usar o mínimo de movimentos e utilizar ao máximo as práticas de assepsia médica, visando diminuir a contaminação do ambiente e do uniforme;

- ao colocar a fronha no travesseiro, afofá-lo;

- considerar a temperatura do ambiente e do paciente, bem como as preferências deste ao dispor as cobertas;

- limpar a unidade com o pano úmido;

- deixar a unidade agradável esteticamente e funcional para o paciente:

- campainha à mão

- mesa de cabeceira próxima à cama, do lado que melhor lhe convier

- cobertas colocadas de modo a permitir livre movimentação dos pés

- objetos pessoais limpos e acessiveis.

NOTA: Quando necessário, colocar impermeável, lençol móvel e cobertores. 


\section{HIGIENE ORAL}

MATERIAL NECESSARIO:

- água

- copo

- escova de dentes

- pasta dental

- cuba rim

- toalha.

\section{NORMAS A SEREM SEGUIDAS}

1. Quanto ao paciente, considerar:

- as suas condições, para determinar a sua dependência da enfermagem;

- seus hábitos;

- suas preferências;

- sua sensibilidade quanto ao estado da sua boca e os odores que possa exalar;

- que a eficiência na remoção de sujidades de todas as faces dos dentes depende de movimentos corretos na escovação;

- os cuidados para evitar lesões na mucosa bucal;

- que o hidrato de carbono é um dos elementos na cadeia de fenômenos que leva à cárie;

- que a saliva remove detritos alimentares;

- que a limpeza da língua, quando saburrosa, é indispensável;

- a freqüência necessária para limpeza da boca;

- a orientação que precisa receber;

- o seu encaminhamento a especialistas em caso de necessidade.

2. Quanto ao material, considerar:

- a possibilidade de usar objetos pessoais do paciente;

- as escovas muito duras podem ferir o paciente e muito moles não atingem os objetivos;

- não só a pasta dental remove sujidades, mas também limão, glicerina, bicarbonato de sódio, sabão, sabonete, dentifrício líquido, etc. 
- a possibilidade de usar desodorante, umectantes e lubrificantes para a mucosa bucal e lábios;

- a possibilidade de improvisar material;

- a proteção do paciente com toalhas;

- a responsabilidade legal do enfermeiro em relação a próteses dentárias.

\section{LAVAGEM DA CABEÇA}

\section{MATERIAL NECESSARIO:}

- sabão líquido

— suco de limão ou vinagre diluídos em água - 30:150 ml

- toalhas

- duas bolas de algodão

- jornal

- papel higiênico

- pente

- caneca graduada

- um ou dois jarros com água quente

- balde

- dois impermeáveis

- cobertor de banho

- ou uma bacia ou recipiente próprio que substitua o balde, o cobertor de banho, um impermeável e um jarro.

\section{NORMAS A SEREM SEGUIDAS}

1. Quanto ao paciente, considerar:

- as suas condições;

- horário e condições do tempo para favorecer a secagem;

- posição confortável e segura;

- proteção das orelhas;

- que o couro cabeludo é muito sensivel ao calor;

- a preferência no uso de sabão líquido e a utilidade do limão ou vinagre para removê-lo;

- que a fricção com as polpas dos dedos ajuda na remoção de toda a sujidade;

- o cuidado para evitar água e sabão nos olhos; 
- a necessidade da secagem rápida do cabelo;

- que os iabus do paciente merecem respeito e orientação.

2. Quanto ao material, considerar:

- a proteção da cama com impermeável e toalhas;

- remoção total do sabão;

- que recipientes menores são mais fáceis de manusear;

-- que recipientes que permitam o escoamento da água facilitam a limpeza;

- dobrar o cobertor em diagonal, enrolá-lo, dar um nó com as duas pontas para formar uma roda . Colocar por dentro desta roda o impermeável dobrado em funil, formando um recipiente com escoadouro.

NOTA: Quando houver possibilidade, escovar os cabelos, colocar cremes, usar xampus da preferência do paciente, enrolar ou prender os cabelos e usar secadores para a secagem do cabelo.

\section{BANHO NO LEITO}

MATERIAL NECESSÁRIO:

- balde

- bacia

- jarro

- cuba rim

- comadre

- jornal

- talco ou creme

- sabonete

- pasta dental

- escova de dentes

- água (fria e quente)

- pano de banho

- pente ou escova

- papel higiênico

- tesoura ou lixa de unhas

- copo 
- toalhas

- roupas de cama

- roupas do paciente

- desodorante

\section{NORMAS A SEREM SEGUIDAS}

1. Quanto ao ambiente e ao executante, considerar:

- a privacidade para o paciente;

- a prevenção de correntes de ar;

- a organização e ordem na economia de tempo e movimento;

- a automatização como fator que facilita o trabalho (seqüência);

- os movimentos que facilitam a remoção mecânica de sujidades;

- o exemplo como método de ensino;

- a mecânica corporal do executante;

- a observação e a anotação como auxiliares no diagnóstico e tratamento;

- que a aceitação do cuidado pelo paciente depende da segurança da pessoa que o ministra.

2. Quanto ao paciente, considerar:

- os objetivos do banho no leito;

- a sua mecânica corporal;

- a sua comodidade durante o banho;

- o seu pudor;

- a evaporação da água sobre superfície exposta como fator de esfriamento do corpo;

- os movimentos do paciente e as massagens como ativadores da circulação;

- as massagens como relaxantes da musculatura;

- a anatomia das articulações do paciente para movimentá-lo com segurança;

- a necessidade do corte das unhas;

- que se deve fazer pelo paciente tudo o que ele não puder fazer;

- que se deve deixar o paciente fazer tudo que puder fazer;

- a necessidade do paciente de sentir-se esteticamente apresentável e sem odores desagradáveis; 
- as suas condições e outros cuidados como: sinais vitais, alimentação, peso, controles de diurese, drenagens, infusões.

3. Quanto ao material, considerar:

- a funcionalidade na distribuição dos objetos do paciente e do material para o banho;

- as toalhas como protetores da cama e do paciente;

- os princípios de capilaridade e atrito para panos e toalhas;

- o sabão como um alergizante em potencial;

- a temperatura da água como fator auxiliar na remoção mecânica de sujudades;

- a temperatura da água como fator de conforto para o paciente;

- a influência da temperatura da água no equilibrio térmico do paciente;

- a temperatura da água como relaxante muscular;

- as dobras na roupa de cama ou no pano de banho como fatores de desconforto;

- as três fases para limpeza: lavar com sabão, removê-lo e enxugar;

- a troca de água sempre que necessário;

- a água corrente como mais eficaz na remoção mecânica de sujidades;

- o pente ou escova de cabelo como distribuidores da oleosidade e removedores de sujidades;

- a vaselina salicilada como ótima no tratamento de hiperqueratose.

\section{CATETERISMO VESICAL}

\section{MATERIAL NECESSARIO:}

- sonda vesical

- pacote de sondagem

- luvas

- cuba rim, contendo: pinça e cuba redonda, com bolas de algodão

- cuba rim para colocar o material utilizado

- recipientes para colher a urina

- solução para a antissepsia local mertiolato incolor (sol. aquosa a 1:20.000)

Permanganato de Potássio - 1:20.000 
Líquido de Dakin

Hexilresorcinol $0,10 \%$

- forro impermeável, lençol ou papel para ser colocado sob o paciente.

\section{NORMAS A SEREM OBSERVADAS}

1. Com relação ao paciente, considerar:

- que o cateterismo vesical é um tratamento traumatizante;

- suas experiências anteriores;

- suas expectativas;

— suas reações de medo;

- a possibilidade de lesão da mucosa uretral e da bexiga;

- a capacidade da bexiga;

— a estrutura e as dimensões da uretra;

- a localização do óstio externo da uretra;

- a possibilidade de contaminação da uretra e bexiga;

- as medidas de assepsia cirúrgica;

- que a bexiga é normalmente uma cavidade estéril;

- a flora do vestíbulo vaginal;

- a necessidade da antissepsia local;

- o esvaziamento lento da bexiga;

- que a posição ginecológica e a de Sims são as melhores para o cateterismo vesical na mulher e o decúbito dorsal é a melhor no homem;

- o relaxamento dos músculos abdominais e do períneo.

2. Com relação ao material, considerar:

- que o cateterismo vesical é uma prática de assepsia cirúrgica;

- a existência de bons antissépticos não irritantes para as mucosas;

o calibre das sondas vesicais: de $n .^{\circ} 12$ a 14 para adultos de n. 6 a 10 para crianças;

- que, para o material a ser colhido, são necessários recipientes apropriados e devidamente identificados. 
3. Com relação ao ambiente, considerar:

- privacidade;

— iluminação adequada;

- móveis apropriados para acomodação do paciente e disposição do material.

\section{ENTEROCLISMA}

MATERIAL NECESSARIO:

- sonda retal

- lubrificante

- papel higiênico

- cuba rim

- comadre

— solução prescrita

- forro impermeável, lençol ou papel para ser colocado sob o paciente.

MATERIAL ESPECIFICO para lavagem intestinal:

-. irrigador

- tubo de borracha

- pinça

- suporte para irrigador.

MATERIAL ESPECIFICO para clister:

- funil pequeno ou seringa de $50 \mathrm{ml}$ ou pera de borracha

- recipiente graduado para solução prescrita.

NOTA: Material industrializado para clister, pode conter a droga prescrita ou na forma de cristais para serem diluídos ou já na forma de solução.

\section{NORMAS A SEREM OBSERVADAS}

1. Com relação ao paciente, considerar:

- o relaxamento dos músculos abdominais e do períneo;

- a estrutura e dimensão do intestino grosso;

- a mucosa intestinal como membrana osmótica; 
- os movimentos peristálticos;

- a capacidade do cólon:

- a necessidade de lubrificação da sonda retal para facilitar a introdução;

- a possibilidade de obstáculos, dor e lesões à introdução da sonda;

- o controle da eliminação da matéria fecal e do líquido introduzido;

- a possibilidade de condicionamento da eliminação intestinal pelo uso freqüente do enteroclisma;

- a posição de Sims como a mais anatômica;

- o tempo de retenção do enteroclisma.

2. Com relação ao material, considerar

- o calibre das sondas de $n .^{\circ} 20$ a 32 para adultos e de $n .^{\circ} 14$ a 20 para crianças;

- a contaminação do material pelos parasitas do intestino grosso;

- a possibilidade da utilização do sistema de sifonagem;

- a altura da coluna líquida (pressão hidrostática);

- a velocidade de escoamento dos líquidos.

3. Com relação ao ambiente, considerar:

- privacidade;

- iluminação adequada;

- móveis apropriados para acomodação do paciente e disposição do material;

- sanitário de fácil acesso para o paciente;

- arejamento.

\section{COLHEITA DE SANGUE}

\section{MATERIAL:}

- seringa

- agulha

- garrote

- algodão com álcool

- recipiente apropriado para coleta do sangue

- forro impermeável, plástico ou papel para ser colocado sob o local da punção. 
1. Com relação ao paciente, considerar:

- suas experiências anteriores;

- suas expectativas;

- suas reações de medo;

- o que ele precisa saber;

- o que ele sabe sobre o assunto;

- que o paciente precisa ser observado constantemente;

- que as reações emocionais indesejáveis devem ser prevenidas;

- que sua cooperação depende da orientação que receber;

- que uma posição confortável e correta facilita a colheita;

- as características da veia a ser puncionada;

- que a penetração da agulha dependerá de: fixação da veia, pele esticadä, bisel afiado, ângulo de inserção;

- que o sangue flue da área de maior pressão para a de menor pressão, a fim de manter a estase venosa até a colheita completa;

- a solução de continuidade da veia requer hemostasia imediata;

- a orientação para encaminhamento dos exames e números de dias necessários para obtenção dos resultados.

2. Com relação ao material, considerar:

- o material a ser colhido necessita de recipientes apropriados e devidamente identificados;

- a punção venosa é uma prática de assepsia cirürgica;

- a hemólise poderá ser provocada por pressões exercidas sobre as hemácias;

- o tempo de coagulação do sangue é em média de 3 a 8 minutos;

- existem substâncias anti-coagulantes apropriadas para exames específicos que exigem sangue não coagulado;

- o sangue poderá transportar microrganismos patogênicos;

- o sangue coagulado dificulta a limpeza do material;

- existem substâncias químicas, que dissolvem coágulos sanguíneos. 


\section{CURATIVO}

MATERIAL NECESSARIO:

- carro de curativo com material completo e limpo: soluções

pomadas

- pacote de curativo esterilizado com: pinça dente de rato pinça anatômica pinça de Kocker

- esparadrapo

- gaze

- pasta de algodão

- ataduras

- tesoura ou lâmina cortante

- pinça servente

- espátulas

- balde

- bacia

- cuba rim.

NOTA: Em caso de "curativo contaminado", acrescentar ao material: luvas e uma bacia contendo solução desinfetante para receber as pinças e as luvas logo após o uso.

NORMAS A SEREM OBSERVADAS

1. Com relação ao paciente, considerar:

- suas necessidades, a fim de planejar bem o curativo;

- os objetivos do curativo;

- tipos e características da ferida;

- tipo e característica do curativo;

- processo normal de restauração dos tecidos;

- processo de cicatrização por granulação;

- a assepsia como requisitante básico para um curativo correto;

- limpeza da ferida partindo: do centro para a periferia; 
do mais limpo para o menos limpo;

do menos contaminado para o mais contaminado.

- que sempre a ferida é considerada como potencialmente infectada;

- a sensibilidade dos tecidos expostos;

- as reações do paciente em relação às lesões corpóreas;

- a possibilidade de infecção;

- a observação de sinais e sintomas de infeç̧ão;

- o conforto durante e após o curativo;

- a escolha do horário para o curativo.

2. Con relação ao material, considerar:

- material completo;

- esterilidade;

- determinação de áreas: contaminadas, limpas e estéreis;

- a reserva de material esterilizado na clínica;

- disposição de modo a facilitar o trabalho;

- facilidades físicas para a antissepsia das mãos;

- a seleção de pomadas e antissépticos em vista das indicações específicas;

- a possibilidade de contaminação por germes altamente patogênicos.

3. Com relação ao ambiente, considerar as seguintes condições:

- limpeza;

- iluminação;

- privacidades;

- espaço para trabalho;

- diminuição da corrente de ar;

- diminuição da circulação de pessoas;

- diminuição de movimentos do executante e do paciente. 
Soluções e pomadas comumente utilizadas para curativo

\section{SOLUÇOEES}

- Solução fisiológica $(0,9 \%) \ldots$. .

- Alcool

- Éter

- Benzina

- Água Oxigenada $\left(\mathrm{H}_{2} \mathrm{O}_{2}\right)$ Vol. 10

- Permanganato de Potássio 1:5-10.000

- Líquido de Dakin (hipoclorito de sódio + ácido bórico) $0,5 \% \ldots$

- Nitrato de Prata — 1:1.000 ...

- Mercúrio cromo ou Mercurocromo 1 a $2 \%$.............

- Mertiolato a $1 \%$ (solução alcoólica)

2. POMADAS

- Furacin (Nitrofurazona ou furacina $-2 \%) \ldots \ldots \ldots \ldots \ldots$

- Neomicina

- Bálsamo de Peru - 5\% ......

- Tintura de Benjoim (sol. alcoólica a $20 \%$ )

\section{INDICAÇÃO E USOS}

Emulsionante para limpeza.

Antisséptico.

Dissolvente para limpeza.

Dissolvente (esparadrapo).

Antisséptico, oxidante; reage com a ca. tálase. Não colocar em cavidades profundas.

Pode ser usado na homeostasia; antisséptico, antimicótico, oxidante, adstringente; desodorante. Liberta oxigênio em contato com a matéria orgânica. Sua ação é favorecida quando aquecida.

Ótimo antisséptico; não é irritante, mesmo para mucosa e tecido de granulação.

Antisséptico para as mucosas. A $1 \%$ é utilizado no método de Credé.

Antissepsia da pele e mucosa. Não colocar diretamente sobre tecidos expostos por solução de continuidade.

Antissepsia da pele.

Antissepsia das mucosas e das feridas.

Age sobre os germes Gram positivos e negativos. Dotada de amplo espectro de atividade.

Antibiótico que age sobre os Gram positivos e negativos.

Óleo resina obtido de um vegetal antisséptico para feridas e tratamento de parasitoses cutâneas. Favorece a cicatrização.

Forma uma película sobre a pele. Passada sobre a pele íntegra diminui o aparecimento de lesões. 


\section{DIURESE}

\section{MATERIAL NECESSARIO:}

- cálice graduado (ou outro objeto para medir)

- jornais

- papel higiênico

- papel e lápis

- frasco coletor

- sabão líquido

- recipiente para despejos

- densímetro e proveta, se necessário

- frascos de amostra, se necessário.

\section{NORMAS A SEREM OBSERVADAS}

1. Quanto ao paciente, considerar:

- anotação precisa no relatório de enfermagem e no gráfico;

- a correlação dos dados obtidos com: peso, diagnóstico, medicação, dieta, eliminaçôes, indicação do controle de diurese.

2. Quanto ao material, considerar:

- a necessidade de ter todo o material à mão;

- a proteção do material para diminuir a contaminação;

- o conhecimento do material - ex: escala do cálice graduado;

- a exatidão na medida e verificação das características da urina;

- a possibilidade de ser necessária uma amostra da urina para exame de laboratório;

- a limpeza do material após a medida;

- a identificação dos frascos coletores;

- a anotação imediata em papel ou livro dos dados obtidos de cada paciente;

- a possibilidade de ser necessária a medida da densidade da urina.

3. Quanto as ambiente, considerar:

- a proteção do local (com papel) para diminuir a contaminação;

- a distribuição funcional do material;

- äreas limpas e contaminadas;

- o arejamento e a iluminação;

- a proximidade do vaso sanitário. 


\section{SINAIS VITAIS}

\section{MATERIAL NECESSARIO}

- termômetro

- aparelho de pressão e estetoscópio

- relógio de pulso com ponteiro de segundos

- lápis bicolor bem apontado ou canetas azul e vermelha

- recipiente para termômetro com solução desinfetante

- saquinho de papel ou bandeja de papel

— bolas de algodão: com álcool

- gráficos ou papel sem álcool

- régua.

\section{NORMAS A SEREM OBSERVADAS}

1. Com relação ao paciente, considerar:

- a comodidade do paciente;

- a precisão dos dados colhidos;

- a correlação dos dados colhidos com outras condições do paciente;

- a importância das alterações encontradas, de sua notificação e das providências a serem tomadas;

- a freqüência com que estes dados devem ser colhidos.

2. Com relação an material, considerar:

- a fragilidade dos instrumentos;

- o funcionamento dos instrumentos;

- o uso das técnicas da assepsia médica;

- a colocação correta de cada instrumento no paciente;

- o uso da régua e lápis bicolor, com observação das convenções usadas pelas instituições.

3. Com relação ao executante, considerar:

- o valor dos dados colhidos como indicadores de saúde;

- a seqüência no trabalho; 
- a economia de tempo e movimentos;

- o controle pessoal para não alarmar o paciente.

PAUlA, N. S. de; MARQUES, M. H. de O.; KAMIYAMA, Y.; HORTA, W. de A. Standards to be observed in basic nursing procedures. Rev. Esc. Enf. USP, São Paulo, 13(3) :233-250, 1979.

The authors present as an aid to teaching, a guide of some basic nursing procedures, described according to the norms to be observed. 